NBER WORKING PAPER SERIES

\title{
THE DECLINING EFFECTS OF OSHA INSPECTIONS ON MANUFACTURING INJURIES: 1979 TO 1998
}

\author{
Wayne B. Gray \\ John M. Mendeloff \\ Working Paper 9119 \\ http://www.nber.org/papers/w9119 \\ NATIONAL BUREAU OF ECONOMIC RESEARCH \\ 1050 Massachusetts Avenue \\ Cambridge, MA 02138
}

August 2002

We are grateful to several agencies for financial support: to the National Institute of Occupational Safety and Health (R01-OH03895-03) for this analysis and the creation of the 1992-98 data set, to the National Science Foundation (SES-8420920) for creation of the 1979-85 data, and to the Bureau of Labor Statistics (research contract J-9-J-5-0085) for creation of the 1987-91 data. We would also like to thank John Ruser, John Scholz, and David Weil for valuable comments on an earlier draft of this manuscript, and Nichola Thomson for research assistance. The research was conducted with restricted access to Bureau of Labor Statistics (BLS) data on-site at the BLS. The views expressed here are those of the authors, and do not necessarily reflect the views of the BLS or other supporting agencies. The views expressed herein are those of the authors and not necessarily those of the National Bureau of Economic Research.

(C) 2002 by Wayne B. Gray and John M. Mendeloff. All rights reserved. Short sections of text, not to exceed two paragraphs, may be quoted without explicit permission provided that full credit, including (C) notice, is given to the source. 
The Declining Effects of OSHA Inspections on Manufacturing Injuries: 1979 to 1998

Wayne B. Gray and John M. Mendeloff

NBER Working Paper No. 9119

August 2002

JEL No. J28

\begin{abstract}
This study compares the impact of OSHA inspections on manufacturing industries using data from three time periods: 1979-85, 1987-91, and 1992-98. We find substantial declines in the impact of OSHA inspections since 1979-85. In the earliest period we estimate that having an OSHA inspection that imposed a penalty reduces injuries by about $15 \%$; in the later periods it falls to $8 \%$ in $1987-91$ and to $1 \%$ (and statistically insignificant) in 1992-98. Testing for different effects by inspection type, employment size, and industry, we find differences across size classes, but these cannot explain the overall decline. In fact, we find reductions in OSHA's impact over time for nearly all subgroups we examine, so shifts across subgroups cannot explain the whole decline. We examine various other hypotheses concerning the declining impact, but in the end we are not able to provide a clear explanation for the decline.
\end{abstract}

Wayne B. Gray

Economics Department

Clark University

950 Main Street

Worcester, MA 01610

and NBER

wgray@clarku.edu

\author{
John Mendeloff \\ Graduate School of Public and \\ International Affairs \\ University of Pittsburgh \\ 3E34 Forbes Quad \\ Pittsburgh, PA 15260 \\ jmen@birch.gspia.pitt.edu
}




\section{Introduction}

Congress established the Occupational Safety and Health Administration (OSHA) in 1970 to prevent occupational injuries and illnesses, and there has been considerable debate since then over the effectiveness of the program. OSHA does tens of thousands of inspections, and imposes millions of dollars in penalties each year, but most workplaces are only rarely visited, penalties are low relative to the cost of abating many workplace hazards, and many injuries are unrelated to OSHA standards.

Many empirical studies examining OSHA have found little evidence of an impact on injuries (e.g. Smith (1979), Viscusi (1979, 1986), McCaffrey (1983), Bartel and Thomas (1985), Ruser and Smith (1991)). By contrast, a series of studies by Scholz and Gray found significant impacts, using a large plant-level database for the 1979-85 period. Depending on the analytical technique used, having an OSHA inspection which imposed a penalty was associated with a 15-22\% decline in injuries over a three year period (Scholz and Gray (1990), Gray and Scholz (1993)).

The present study extends these analyses to more recent years. To the 1979-85 dataset used by Scholz and Gray we add a 1987-91 dataset created earlier by one of the authors (Gray (1996)), and a final 1992-98 data set created for this study. Although there are some differences in sample composition across the three data sets, we use the same variables and analyses for all three data sets to make the results as comparable as possible.

We find that the average impact of OSHA inspections on changes in injury rates has declined substantially over time, especially in the most recent data set, where the overall impact is no longer statistically significant. Using our basic model, the point estimate of the impact of an OSHA penalty inspection declines from $15 \%$ in the early 1980 s to $8 \%$ in the 
late 1980s and about 1\% in the 1990s. Models which include all OSHA inspections (with and without penalties) show smaller impacts, but these impacts also decline across the three periods.

We looked for different impacts across various subgroups: inspection types, establishment sizes, and industries. We do observe smaller impacts in the largest establishments. However, we observe declines over time in the impact of OSHA inspections on injuries within nearly all subgroups we examine, although the declines occur to different degrees and at different times. The paper also examines a variety of possible explanations for the decline in impact, but we aren't able to provide a clear explanation for the decline.

The following section of the paper provides some background on the determinants of occupational injuries and OSHA's activity. Section 3 discusses the data and some econometric issues affecting the analysis. Section 4 presents the results, and Section 5 summarizes the findings.

\section{Background and Theory}

Figure 1 shows the injury rate per 100 full-time manufacturing workers from 1972 to 1999. The numbers are based on reporting to the annual Survey of Occupational Injuries and Illnesses, conducted by the Bureau of Labor Statistics (BLS). The "lost workday case rate" is divided into two categories: cases with days away from work and cases with only restricted work activity. The rate for all lost workday cases changed relatively little from 1972 until the early 1990s, except for the expected cyclical changes. Injury rates typically 
fall in recessions and increase in booms, primarily because of the changes in the number of newly hired, inexperienced workers (Robinson (1988)). However, in the 1990s the manufacturing injury rate dropped by about $25 \%$ despite continuous prosperity during those years. We also see in Figure 1 that the rate of injuries with restricted work activity rose substantially after the mid-1980s while the rate for cases with days away from work accounted for the decline in the 1990s (we return to this issue later).

OSHA may affect injuries through several possible mechanisms (Mendeloff (1979)). The agency enforces a set of safety and health standards and may create new standards. It also provides information to employers and employees, both directly through consultations and training activities and through the provision of educational materials. Most of OSHA's resources are devoted to its enforcement program. Inspections, backed up by the threat of penalties for non-compliance, may push employers to comply with standards or even to improve their overall safety programs. The threat of inspection may also generate compliance actions in order to avoid expected penalties. Even though most workplaces are inspected infrequently, especially in industries with low injury rates, the ability of workers to request OSHA inspections enhances their potential deterrent effect.

Equation (1) below summarizes a variety of factors that may influence the riskiness of working at plant $\mathrm{i}$ in year $\mathrm{t}\left(\mathrm{RISK}_{\mathrm{it}}\right)$. We begin with the inherent hazardousness of the plant which may change over time $\left(H A Z A R D_{i t}\right)$, the average experience or inexperience of the plant's workforce $\left(\mathrm{EXPER}_{\mathrm{it}}\right)$, and the degree of worker fatigue (FATIGUE $\mathrm{Fit}_{\mathrm{it}}$. In addition we have three factors affecting the attention paid by the plant to safety issues. The degree of general deterrence achieved by OSHA inspections at other plants in the same area and industry $\left(\mathrm{GEN}_{\mathrm{it}}\right)$ depends on both the expected probability of being inspected and the 
expected penalty for a violation (with penalty and probability getting equal weight if the firm is risk-neutral). There may be a separate impact of current or past inspections happening at this specific plant (INSP $\mathrm{it-s}_{\mathrm{s}}$ ), either because having an inspection leads the plant to revise its expectations on the probability of future inspections or because OSHA follows up some inspections to ensure that hazards are corrected, with the possibility of much higher 'failure to abate' penalties. ATTEN $\mathrm{it}_{\text {it }}$ includes any other factors such as plant unionization or workers compensation costs which could affect attention to safety.

$$
\text { RISK }_{i t}=f\left(H_{A Z A R D} \text { it, EXPER } i t, \text { FATIGUE }_{i t}, \text { GEN }_{i t}, \text { INSP }_{i t-s}, \text { ATTEN }_{i t}\right) .
$$

The actual number of injuries occurring in a workplace in a given year will depend strongly on the underlying riskiness, along with some random error term. These errors may be greater (in percentage terms) in smaller workplaces. To the extent that unusually high injuries at time t-1 leads to increased attention to safety issues at time $t$, we would expect some degree of negative autocorrelation in the unobserved random element of injuries.

\section{Data and Econometric Issues}

The basic sample universe for the data sets has remained unchanged from the original Scholz and Gray data set: establishments that are in manufacturing industries and are located in states where OSHA has primary enforcement responsibility (the 29 "FederalOSHA" states, which include about $60 \%$ of the national work force). Manufacturing workplaces have long been a focus of OSHA activity and are longer-lived and better-defined than workplaces in other sectors (such as construction). This is important, since we allow 
OSHA inspections to affect injuries over several years. Information on injuries at the establishments is merged with characteristics of OSHA inspections at those establishments to create the analysis data sets.

Our injury data comes from the Bureau of Labor Statistics (BLS) Survey of Occupational Injuries and Illnesses which gathers data for hundreds of thousands of establishments each year in a stratified sampling process that results in larger establishments being more likely to be in the sample. Since we look at changes in an establishment's injuries over time we focus on those establishments that have BLS injury data for consecutive years. This necessarily results in large establishments being over-represented in our data sets, relative to all manufacturing establishments. We use the total number of lostworkday injuries during the year as our injury measure. Earlier work with the first two data sets also examined a measure of the seriousness of the injuries, the total number of days of work lost due to injuries at the plant; but that information is not present in the revised version of the BLS Survey which was begun in 1992.

The BLS data is combined with information on OSHA inspections from OSHA's Integrated Management Information System (IMIS). Our key measure of inspection activity (in addition to the year of the inspection) is whether or not a penalty was imposed. ${ }^{1}$ We consider only two types of inspections: programmed inspections, targeted by OSHA based on industry hazardousness, and complaint inspections, where OSHA is responding to a written worker complaint. These two types account for over $80 \%$ of all inspections during the time period studied. ${ }^{2}$ For almost all of the period examined in this paper, OSHA targeted its programmed inspections by first identifying all establishments that were in 4-

\footnotetext{
${ }^{1}$ As reported in Scholz and Gray (1990), having a serious violation cited during the inspection is essentially equivalent to having a penalty (95-99\% overlap in our data).
} 
digit SICs with rates above a state's manufacturing average (Siskind (1993)). Then, it chose inspection sites randomly within this set, excluding only those workplaces with fewer than 11 workers or those where OSHA had conducted a comprehensive inspection within the previous 2 years. Complaint inspections were initiated by a written (formal) or oral (informal) notice from a worker (or a union representative) about an alleged violation or hazard at a workplace

The OSHA and BLS records were linked together, using name and address information to identify records that referred to the same establishment in a technique developed by Fellegi and Sunter (1969) that calculates the probabilities of two records matching, based on agreement or disagreement on their characteristics. The matching methodology is explained in more detail in Gray (1996).

Since our analysis focuses on injury changes, two consecutive years of BLS data are needed to generate one observation for analysis. Table 1 describes some features of the 3 data sets. The original Scholz and Gray data set was restricted to those manufacturing establishments which had BLS injury data available for all 7 of the years from 1979 and 1985 , but a broader definition was needed in the later samples due to substantial cuts in the BLS Survey sample size later in the 1980s. The 1987-91 dataset included all plants with at least 2 consecutive years of BLS Survey data; the 1992-98 dataset includes all plants with at least 3 consecutive years. If we had instead insisted on 7 years of BLS Survey data in 199298, the size distribution would have been seriously skewed: of the 860 establishments with 7 years of data, only 21 had fewer than 100 employees and only 60 had fewer than 250 . This would have precluded any analysis of OSHA's impact in those smaller size groups which receive the majority of OSHA inspections.

\footnotetext{
${ }^{2}$ Calculated from OSHA IMIS data for inspections of manufacturing plants in federal OSHA states.
} 
The basic model estimated by Scholz and Gray took the following form:

(2) $\operatorname{DINJ}_{i_{t}}=a_{t}+b_{0} \operatorname{INSP}_{i t}+b_{1} \operatorname{INSP}_{i t-1}+b_{2} \operatorname{INSP}_{i t-2}+b_{3} \operatorname{INSP}_{i t-3}+$

$$
\mathrm{c}_{1} \mathrm{DEMP}_{\mathrm{it}}+\mathrm{c}_{2} \mathrm{DHRS}_{\mathrm{it}}+\mathrm{SIC}_{\mathrm{i}}+\mathrm{u}_{\mathrm{it}}
$$

The dependent variable (DINJ) is the log of the change in the number of injuries, so the coefficients show the impact on the percentage change in injuries. Gray and Scholz (1993) report extensive tests with alternative specifications. Since OSHA targets inspections at high-injury-rate establishments, regressions of injury levels on inspections show a positive (endogenous) relationship. They find that using injury changes greatly reduces the endogeneity problem, and we follow this specification.

Our focus is on the specific deterrence impact of OSHA inspections at this particular plant. This impact is captured with four inspection dummies (from $\operatorname{INSP}_{\text {it }}$ to INSP $_{\text {it-3 }}$ ), so the 1983-84 change in injuries depends on four years of inspections (from 1981 to 1984). An alternative OSHA measure, IPEN, refers to inspections which imposed a penalty (following Scholz and Gray (1990)). In some models we allow for different impacts for different inspection types, IPRG and ICMP for any programmed and complaint inspections, and IPRGP and ICMPP for programmed and complaint inspections imposing penalties.

Relating the other explanatory factors to those in Equation (1), we use changes in employment $\left(\mathrm{DEMP}_{\mathrm{it}}\right)$ to measure changes in the experience of the workforce and changes in hours $\left(\mathrm{DHRS}_{\mathrm{it}}\right)$ to measure changes in worker fatigue. To the extent that innate hazardousness is fixed at a workplace, it will be differenced out of the model in change 
form. Trends in industry hazardousness or changes in general deterrence are measured by industry dummies $\left(\mathrm{SIC} 2_{\mathrm{i}}\right)$. In some of our analyses we allow for differences in the impacts of OSHA inspections for establishments in different employment size categories $(1-99,100-$ $249,250-499$, and 500+). When we do so, we include three employment size dummies in the regressions.

In some models we estimate different impacts of OSHA inspections for each 2-digit SIC industry in each period. We then compare the estimated impacts with three different industry-specific factors. First is the extent of general deterrence, measured by the number of OSHA inspections per 1000 production workers in the federal OSHA states. ${ }^{3}$ Second is the industry hazardousness, measured by the industry lost workday injury rate (taken from the BLS web site, www.bls.gov). Third is the industry's new capital investment divided by its existing capital stock, since newer machinery is expected to be safer. ${ }^{4}$

One issue that arises when comparing the results here with the published results of the earlier studies is the choice of estimation method. All of the results presented here are based on ordinary least squares regressions. Earlier studies (such as Scholz and Gray (1990)) allowed for autoregressive errors, recognizing the possibility that shocks to injuries in one year might increase attention to safety, generating negative autocorrelation or regression to the mean in the injury generating process. We experimented with estimating an autoregressive model with the newest data set, and found that while the autoregressive terms were estimated to be significant, the results for the inspection variables were essentially unchanged from those reported here (results available on request).

${ }^{3}$ OSHA inspection totals from website: http://www/osha.gov. Data on production workers from Employment and Earnings, various issues.

${ }^{\frac{1}{4}}$ The data came from the NBER-CES Manufacturing Industry Database, which contains data only through 1996 , so the $1992-98$ period uses the $1992-96$ average instead. 
More importantly, some of the earlier analyses of data from 1979-85 and 1987-91 used a 'Chamberlain' model (Chamberlain $(1982,1984))$, which allows for the possibility that inspection targeting leads the set of plants selected for inspections to include more plants with poor performance in terms of injury growth (Gray and Scholz (1993), Gray (1996)). Correcting for this selection effect results in a greater (negative) impact of inspections on injury growth, with the model concluding that the inspected plants would have done even worse if they had not been inspected. In the earlier research, using the Chamberlain method increased the estimated impact of an inspection with penalty in the $1979-1985$ period by $7 \%$, from $15 \%$ to $22 \%$. Using the $1987-1991$ period the comparable impact also rose by $7 \%$, from $8 \%$ to $15 \%$.

Preliminary estimates of the Chamberlain model for the most recent period suggest a similar impact (the reduction in injuries after a penalty inspection increases in magnitude from about $1 \%$ using ordinary regression to about $7 \%$ using the Chamberlain model). Thus the comparison across time periods gives a similar conclusion to the ordinary regression results presented here, with a substantial reduction in the impact of an inspection with penalty between Period 1 and Period 3. We concentrate on ordinary regression results in this paper primarily because the Chamberlain estimation method requires complete injury data, and hence can only be calculated for a small and unrepresentative minority of the plants in the 1992-1998 period (860 plants, nearly all of them in the larger size categories, with more than 250 employees). 


\section{Results}

Table 1 presents the means of the variables in the three data sets. There is a decline in injuries over time (negative DINJ) within each of the three data sets. However, this does not mean that rates declined continuously from Period 1 to Period 3. Each period happens to begin when rates were fairly high and end when they were lower. The establishment size distribution differs somewhat between the three data sets, based on changes in the BLS Survey coverage and the number of years of injury data required for inclusion. The period 2 data set contains more small plants, since it only required two consecutive years of injury data; the latest data set contains a higher proportion of large plants, due to the steady shrinkage in the BLS Survey sample size.

Table 1 also reveals some substantial changes in OSHA inspection activity across the three data sets. In the earliest data set there were relatively high rates of inspections (INSP), especially programmed inspections (IPRG). These inspections commonly failed to impose penalties; only about one-third of all years with inspections had any inspections that imposed penalties (IPEN), but in the later two periods this ratio was reversed. This pattern can be explained by the existence of "records-check" inspections during the early 1980s; these inspections began with a check of the plant's injury rate records and stopped there if the plant's injury rate was below the average rate for manufacturing (Siskind (1993)). This led to a large set of programmed inspections that did not impose a penalty (and did not perform a 'real' inspection of the workplace).

There was also some variation in the composition of inspections across the periods. Because of the prevalence of programmed inspections (IPRG) in the first period, they greatly outnumbered complaint (ICMP) inspections (.19 to .06). In the later periods the 
probability of a complaint inspection rose slightly (to .07), while the probability of a programmed inspection fell dramatically (to .03). There was also an increase in the fraction of complaint inspections which imposed penalties (ICMPP) over time, though not as dramatic as the increase noted above for programmed inspections (IPRGP).

Table 2 shows the basic regressions of injury changes on inspections and inspections with penalty. The first column presents results from the original Scholz and Gray data set from 1979-85. The second and third columns present results from the 1987-91 and 1992-98 data sets. As expected, growth in employment and hours worked increases the number of injuries. Perhaps due to the 'random' nature of workplace accidents, the models only explain about $12 \%$ of the variance in injury changes across plants in the earlier two periods, declining to about $9 \%$ in the latest period.

As found in the Scholz and Gray analysis, inspections with penalties have a larger impact than other inspections (comparing IPEN with INSP). The main result in Table 2 is that both IPEN and INSP coefficients became smaller in each succeeding period. Adding up the cumulative IPEN effect in each period, it declines from $15.7 \%$ to $9.4 \%$, then to $1.4 \%$, with the last period's impact not statistically significant. We also combined data from all 3 periods in order to formally compare the IPEN coefficients across periods. The results (not shown) confirm that the Period 3 results are significantly different from those in Period 1.

In Table 3 we see the impact of combining the four years of OSHA inspections into a single variable. IPENX shows the average impact of an inspection over a four year period, so the cumulative impact is falling from $19.2 \%$ to $12.0 \%$ to $1.2 \%$ across the three periods. Comparable regressions for each period including both IPENX and inspections with no penalty (NOPENX) always found insignificant coefficients on NOPENX (results available). 
The initial regression results presented in Tables 2 and 3 provide evidence of a substantial decline in the measured impact of OSHA inspections on manufacturing industries. We now consider different categories of inspections and establishments to see how widespread the decline is. Looking at inspection type, Scholz and Gray (1997) found that both complaint and programmed inspections affected injuries, but that complaint inspections were less dependent on penalties for their impact. Table 4 shows the impact of complaint and programmed inspections on injuries in each of the periods, confirming that programmed inspections are more dependent on penalties for their impact. The impact of complaint inspections with penalties declines more in the 1980s, while the impact of programmed inspections with penalties declines more in the 1990s. However, these differences between the inspection types were not statistically significant.

Next we allow the impact of OSHA inspections to differ depending on characteristics of the establishment. Table 5 examines the effects of inspections with penalties in 4 different establishment employment size categories: small, under 100; medium, 100-249; big, 250-499; and very big, over 500. We find much weaker preventive effects of inspections in the largest establishments compared to the smaller establishments (similar to results reported in Gray and Scholz (1991)). As expected, the model does a better job of explaining the variation in number of injuries for larger workplaces. More importantly we have declines in the estimated impact across the periods for nearly all cases, and always smaller impacts in Period 3 than in Period 1. The timing of the decline varies across size classes, but the decline is statistically significant for all but the medium plants.

Next we allowed for different OSHA impacts across different industries, shown in Table 6. Examining the model for all 3 periods together, we added interaction terms 
between IPENX and two-digit SIC manufacturing industry dummies. Each interaction term provides an estimate of the effect at an establishment in that industry of having at least 1 inspection with penalty over a four year period. There are a few significant industry coefficients, but there is no industry where the effect of inspections with penalties is significant in more than one period. Not surprisingly, there is no significant correlation across industries in their coefficients for different periods.

Table 7 tests whether these industry-period coefficients are correlated with three factors that might affect OSHA's impact: the average lost workday injury rate in the industry (bigger effects if there are more injuries per worker to prevent), the average inspection rate in the industry (smaller effects when firms are expecting OSHA inspections), and the average investment rate in the industry (smaller effects where there is newer, safer machinery). These correlations are relatively small, and only two approach significance. For industry coefficients based on all workplaces, higher investment rates were weakly linked to smaller inspection impacts. Looking at workplaces with fewer than 250 workers (where the effects were relatively larger in the last period), the link with investment rates disappears but a weak negative relationship appears with the industry inspection rate.

Finally, we consider the possibility that OSHA inspections have different impacts on different types of injuries. Table 8 shows the results for our basic model, separated into cases with days away from work (DAW) and cases with only restricted work activity (RWA). One clear finding is that, even in Period 1, all of the impact of inspections with penalties was on DAW injuries. There was no impact on RWA injuries. In Period 2, there is even some indication that inspections were linked to increases in RWA injuries, but this disappears in Period 3. 


\section{Discussion and Conclusions}

The initial regression results presented in Tables 2 and 3 provide evidence of a substantial decline between 1979 and 1998 in the measured impact of OSHA inspections on manufacturing industries: from a 15\% reduction over the three years after an inspection with penalty in Period 1, to a $1 \%$ reduction in Period 3. In this section we consider several possible explanations for the decline, based on changes in OSHA policy and injury reporting during this time, and relate them to our statistical results.

One explanation for the decline could be a composition effect, with the data for Period 3 inspections containing more observations where OSHA's impact is small. Table 5 does show a smaller impact for large plants, which are more common in our data for Period 3 than they were in Period 1. This turns out to be offset by shifts in other groups, so the predicted average impact is actually higher in Period $3 .^{5}$ More importantly, the results for all subgroups of the data show that the decline in OSHA's impact is wide-spread, affecting different inspection types, plant sizes, and industries, so it is unlikely that any composition effects could tell the whole story.

Other explanations for the decline could arise from measurement issues. During most of Period 1 (1981-86) OSHA inspectors on programmed inspections followed a "records- check" procedure: first checking a workplace's lost workday injury and illness rate, and terminating the inspection if the rate was below the manufacturing average. Such "records-only" inspections never imposed penalties, so firms wishing to avoid OSHA

\footnotetext{
${ }^{5}$ The predicted impact was obtained by multiplying the Period 1 coefficients for each size group in Table 5 by that group's share of plants in each of the periods from Table 1.
} 
inspections had an incentive to under-report injuries. Ruser and Smith $(1988,1991)$ found evidence that lost workday rates fell for some plants subject to these inspections, but only for uninspected establishments. This would lead our results to understate (not overstate) the impact of inspections on injuries in the earlier period.

Injury reporting might also have been affected by OSHA's "egregious case" policy, which started levying extremely large and highly publicized fines for recordkeeping violations in 1986; if underreporting declined more at inspected establishments than uninspected ones this would translate into a smaller observed OSHA impact. Still, this seems unlikely to have played a large role in the observed decline, since it would explain only the Period 2 changes, not the continuing decline in Period 3.

Another reason why OSHA's records-check policy might affect our cross-period comparison is that plants with penalty inspections would include a disproportionate number with unusually high pre-inspection injury rates (since they weren't records-only). These high rates might then be expected to decline in the years following the inspection (a phenomenon known as "regression to the mean"). Scholz and Gray (1990) account for this using a model with autoregressive errors and find that there was evidence of negative autoregression (consistent with regression to the mean), but that the estimated OSHA impacts were not affected. As noted earlier, we also examined autoregressive models and found they didn't affect our results. Even if regression to the mean led us to overstate our Period 1 results, that should have led the decline in OSHA's impact in later periods to be concentrated in the results for programmed inspections, and to happen by Period 2. Table 4 shows a greater decline in the 1980s for complaint inspections with penalty, which were not 
subject to the records-check policy; the decline in impact for programmed inspections doesn't come until the 1990s, well after the records-check policy was being discontinued.

A final reporting issue arises due to the steady growth since the mid-1980s in the percentage of lost workday injuries that are classified as "restricted work activity" cases rather than as cases with "days away from work." As Figure 1 showed, the rate of RWA cases grew very slowly until the mid 1980s, then almost doubled in the 2 years from 1986 to 1988 and continued growing at over $10 \%$ per year until 1995. Thus by 1996 about $1 / 2$ of all lost workday cases in manufacturing did not involve days away from work. We saw in Table 8 that in every period, even 1979-85, OSHA inspections with penalties had no preventive impact on the percentage change in the number of RWA injuries. Based on an assumption of zero impact on RWA cases, over one-third of the drop in OSHA's impact could be accounted for by the growth of RWA cases. Of course, this is an explanation only in an accounting sense; it provides no causal insights about why RWA cases have not been affected. Indeed, since the growth in RWA cases in the more recent periods presumably comes from cases that formerly would have been DAW cases, it is a puzzle why they are not affected similarly by OSHA inspections.

We now turn to explanations for the decline in OSHA's impact that do not rely on reporting changes or mismeasurement issues. A large increase in general deterrence could in theory weaken the impact of specific deterrence that we measure, but the evidence in Table 7 goes the other way: higher industry inspection rates are associated with more negative (larger) inspection-specific impacts. This reversed sign (if believable) could explain a small part of the decline in impact by the 1990s, when the number of inspections fell by more than one-third and total penalties fell as well. 
Another possible explanation is declining marginal effectiveness of repeated inspections at the same workplace. Evidence for this has been found in past research (Weil (2001), Gray and Jones (1991)). Since larger establishments are inspected more frequently, the greater erosion in effectiveness that we find in the largest size group from Period 1 to Period 2 and then in the next largest from Period 2 to Period 3 is consistent with declining marginal effectiveness. The problem with this explanation is that OSHA had been conducting inspections for nearly a decade before our Period 1 , and the declining impact of repeated inspections is most pronounced in the first few inspections, so most of the decline in impact at large, frequently inspected plants should have already occurred by the start of our data in 1979.

A somewhat different explanation for declining effectiveness of inspections could be that the standards that OSHA enforces have become less relevant to injury prevention over time. Most of these standards date from the 1960s or earlier. Changes in manufacturing technologies may have left many of the standards outdated or irrelevant. As a result, we could find either that fewer violations are being detected or that inspections are relevant to a shrinking percentage of injuries. The number of violations cited per manufacturing inspection was substantially lower in the first period (2.4) than in the latter two periods (5.2 and 4.7), contradicting the first of these predictions. The second is harder to assess. The results in Table 7 on investment rates provide a bit of support, since high-investment industries (with newer, safer equipment) show a smaller impact from OSHA inspections, but the effect disappears for those establishments with fewer than 250 workers (the only size group with substantial effects in the last period). 
Rising costs for workers' compensation may have stimulated employers to increase their efforts to a) prevent injuries, b) discourage workers from making claims, and c) manage the disability process more closely to reduce the costs of claims. The costs of workers' compensation benefits per days away from work injury rose steadily during the 1980s and peaked in the early 1990s (Statistical Abstract (2001)). Greater attention to workplace safety due to workers' compensation programs may diminish the extra incentives provided by OSHA inspections, but the impact of worker compensation should be on injuries in general, rather than on injuries connected to OSHA standards. Since 1992, the reduction in days away from work injuries (the only category for which we have injury type data) occurred fairly uniformly across different injury types in manufacturing, as shown in Table 9. To the extent that there were differences, the injury types generally believed to be more related to standards such as "caught-in" injuries and falls from heights had less of a decline than those believed to be less related to standards such as "bodily reaction" (overexertion) injuries. This is consistent with a hypothesis that general financial incentives like workers' compensation, rather than inspections, were responsible for the injury decline.

Finally, there may have been some changes in what actually goes on during inspections. In the 1990s, especially after mid-1995, OSHA management de-emphasized the importance of numerical measures of inspection activities (e.g., violations cited). It placed more emphasis on problem solving and being more creative in encouraging firms to reduce workplace hazards. This has led overall to fewer inspections taking more hours of inspector time. These changes might have been expected to make individual inspections more effective, but we find a declining impact of inspections instead. 
After examining a variety of reasons for the decline in impact of OSHA inspections on injuries, we have only found partial explanations. Some possibilities, such as changes in data composition, OSHA's records-check policy, and general deterrence, explain very little or even go the other way. The growth in restricted work activity injuries can explain onethird of the decline in an accounting sense, but this doesn't explain why these injuries are less affected. The increases in workers' compensation costs in the 1980s may have led employers to pay more attention to safety hazards, reducing the incremental incentives to improve safety provided by OSHA inspections. We plan to explore these issues further with more detailed analyses of the 1992-98 data, where we can test OSHA's impact on specific types of injuries. 


\section{References}

Bartel, Ann P. and Lacy Glenn Thomas, "Direct and Indirect Effects of OSHA Regulation: A New Look at OSHA's Impact". Journal of Law and Economics. 1985;28:1-25.

Bureau of Labor Statistics, Nonfatal Injuries and Illnesses . Available at http:// ww.bls.gov/iif/oshwc/osh/os/osnr0011.

Chamberlain, Gary, "Multivariate Regressions Models for Panel Data." Journal of Econometrics. 1982;18:5-46.

, "Panel Data." In: Griliches Z, Intrilligator M, eds. Handbook of

Econometrics. Amsterdam: North-Holland; 1984:1247-1318.

Fellagi, Ivan P. and Alan B. Sunter, "A Theory of Record Linkage." Journal of the American Statistical Association. 1969;64:1183-1210.

Gray, Wayne B., "Construction and Analysis of BLS-OSHA Matched Data Set: Final Report." Prepared under contract to the Bureau of Labor Statistics, June 22, 1996.

Gray, Wayne B. and Carol A. Jones, "Are OSHA Health Inspections Effective? A Longitudinal Study in the Manufacturing Sector." Journal of Human Resources 1991;36:623-653.

Gray, Wayne B and John T. Scholz, "Analyzing the Equity and Efficiency of OSHA Enforcement." Law and Policy 1991;13185-214.

, "Does Regulatory Enforcement Work?: A Longitudinal Study

of OSHA Enforcement." Law and Society Review 1993;27:177-213.

McCaffrey, David P., "An Assessment of OSHA's Recent Effects on Injury Rates.” Journal of Human Resources. 1983;18:131-146.

Mendeloff, John M., Regulating Safety: The Politics and Economics of Occupational Safety and Health Policy. Cambridge, Ma: MIT Press; 1979.

NBER-CES Manufacturing Industry Database, available at the NBER web site: http://www.nber.org/nberces/nbprod96.htm.

Occupational Safety and Health Administration website: http://www/osha.gov.

Robinson, James C., The Rising Long-Term Trend in Occupational Injury Rates. Am J Pub Hlth. 1988;78:276-281. 


\section{References (cont.)}

Ruser, John W. and Robert S. Smith, "The Effect of OSHA Records-Check Inspections on Reported Occupational Injuries in Manufacturing." Journal of Risk and Uncertainty. 1988;1:415-435.

"Re-estimating OSHA's Effects: Have the Data Changed? Journal of Human Resources." 1991;26:212-235.

Scholz, John T. and Wayne B. Gray, "OSHA Enforcement and Workplace Injuries: A Behavioral Approach to Risk Assessment." Journal of Risk and Uncertainty. 1990;3:283305.

, "Can Government Facilitate Cooperation? An Informational Model of OSHA Enforcement," American Journal of Political Science, 1997.

Siskind, Fred B., "Twenty Years of OSHA Federal Enforcement Data." U.S. Department of Labor, Office of the Assistant Secretary for Policy. January 1993.

Smith, Robert S., "The Impact of OSHA Inspections on Manufacturing Injury Rates." Journal of Human Resources. 1979;14:145-170.

U.S. Bureau of Labor Statistics, Employment and Earnings, monthly.

U.S. Census Bureau, Statistical Abstract of the United States, 2000. Washington DC: Government Printing Office, 2001.

Viscusi, W. Kip, "The Impact of Occupational Safety and Health Regulation." Bell Journal of Economics. 1979;10:117-140.

Viscusi, W. Kip, “The Impact of Occupational Safety and Health Regulation, 1973-1983." Rand Journal of Economics. 1986; 17:567-580.

Weil, David, "Assessing OSHA Performance: New Evidence from the Construction Industry." Journal of Policy Analysis and Management. 2001;20:651-674. 


\section{Table 1}

\section{Database Description}

\section{$\underline{1979-1985} \quad \underline{1987-1991} \underline{1992-1998}$}

$\begin{array}{lrrr}\text { Number of Observations } & 27,368 & 32,765 & 25,603 \\ \text { Number of Plants } & 6,842 & 14,386 & 8,161 \\ \text { Plants in BLS Dataset for all years } & 6,842 & 3,118 & 860 \\ \text { Required Continuous Years of BLS Data } & 7 \text { years } & 2 \text { years } & 3 \text { years }\end{array}$

Variable Means by Period

$\underline{1979-1985} \quad \underline{1987-1991} \underline{1992-1998}$

Continuous Variables

$\begin{array}{llrrr}\text { DINJ } & \log \text { change in injuries } & -0.046 & -0.029 & -0.043 \\ \text { DHOUR } & \log \text { change in hours } & -0.024 & -0.032 & -0.011 \\ \text { DNUM } & \text { log change in employment } & -0.046 & -0.029 & -0.043 \\ \text { DDAW } & \log \text { change in DAW injuries } & -0.075 & -0.029 & -0.082 \\ \text { DRWA } & \log \text { change in RWA injuries } & 0.036 & 0.059 & 0.040\end{array}$

Employment Size

$\begin{array}{lllll}\text { SMALL } & \text { employment }<100 & 0.196 & 0.325 & 0.221 \\ \text { MEDIUM } & \text { employment } 100-249 & 0.332 & 0.300 & 0.222 \\ \text { BIG } & \text { employment } 250-499 & 0.239 & 0.181 & 0.240 \\ \text { VERY BIG } & \text { employment 500+ } & 0.232 & 0.194 & 0.316\end{array}$

OSHA Inspection Dummy Variables (years t through t-3)

$\begin{array}{lllll}\text { INSP } & \text { any inspection in year } & 0.244 & 0.119 & 0.082 \\ \text { IPEN } & \text { any penalty inspection } & 0.080 & 0.082 & 0.052 \\ \text { IPRG } & \text { programmed inspection } & 0.193 & 0.045 & 0.026 \\ \text { ICMP } & \text { complaint inspection } & 0.061 & 0.073 & 0.069 \\ \text { IPRGP } & \text { programmed with penalty } & 0.063 & 0.035 & 0.034 \\ \text { ICMPP } & \text { complaint with penalty } & 0.018 & 0.046 & 0.035\end{array}$

OSHA Combined Inspections - (Value of Any of the 4 lagged dummy variables equal 1)

$\begin{array}{llllr}\text { INSPX } & \text { INSP-INSPL3 } & 0.625 & 0.383 & 0.258 \\ \text { IPENX } & \text { IPEN-IPENL3 } & 0.283 & 0.245 & 0.194 \\ \text { IPRGX } & \text { IPRG-IPRGL3 } & 0.522 & 0.228 & 0.112 \\ \text { ICMPX } & \text { ICMP-ICMPL3 } & 0.229 & 0.207 & 0.171 \\ \text { IPRGPX } & \text { IPRGP-IPRGPL3 } & 0.221 & 0.141 & 0.093 \\ \text { ICMPPX } & \text { ICMPP-ICMPPL3 } & 0.086 & 0.124 & 0.113\end{array}$




\section{Table 2}

\section{Impact of OSHA Inspections on Injuries}

(current and last 3 years)

\begin{tabular}{|c|c|c|c|c|c|c|}
\hline PERIOD & $\underline{1979-85}$ & $1987-91$ & $1992-98$ & $1979-85$ & 1987-91 & $1992-98$ \\
\hline INTERCEP & $\begin{array}{l}-0.097 \\
(-6.91)\end{array}$ & $\begin{array}{l}0.088 \\
(6.63)\end{array}$ & $\begin{array}{l}-0.044 \\
(-2.92)\end{array}$ & $\begin{array}{l}-0.094 \\
(-6.53)\end{array}$ & $\begin{array}{l}0.087 \\
(6.46)\end{array}$ & $\begin{array}{l}-0.045 \\
(-2.97)\end{array}$ \\
\hline IPEN & $\begin{array}{l}-0.058 \\
(-4.09)\end{array}$ & $\begin{array}{l}0.004 \\
(0.33)\end{array}$ & $\begin{array}{l}-0.002 \\
(-0.13)\end{array}$ & & & \\
\hline IPENL1 & $\begin{array}{l}-0.046 \\
(-3.22)\end{array}$ & $\begin{array}{l}-0.036 \\
(-2.76)\end{array}$ & $\begin{array}{l}0.010 \\
(0.58)\end{array}$ & & & \\
\hline IPENL2 & $\begin{array}{l}-0.048 \\
(-3.46)\end{array}$ & $\begin{array}{l}-0.016 \\
(-1.18)\end{array}$ & $\begin{array}{l}-0.016 \\
(-0.97)\end{array}$ & & & \\
\hline IPENL3 & $\begin{array}{l}-0.005 \\
(-0.42)\end{array}$ & $\begin{array}{l}-0.046 \\
(-3.37)\end{array}$ & $\begin{array}{l}-0.006 \\
(-0.38)\end{array}$ & & & \\
\hline INSP & & & & $\begin{array}{l}-0.019 \\
(-2.13)\end{array}$ & $\begin{array}{l}0.014 \\
(1.28)\end{array}$ & $\begin{array}{l}0.01 \\
(0.67)\end{array}$ \\
\hline INSPL1 & & & & $\begin{array}{l}-0.025 \\
(-2.76)\end{array}$ & $\begin{array}{l}-0.023 \\
(-2.19)\end{array}$ & $\begin{array}{l}0.006 \\
(0.43)\end{array}$ \\
\hline INSPL2 & & & & $\begin{array}{l}-0.024 \\
(-2.63)\end{array}$ & $\begin{array}{l}0.003 \\
(0.28)\end{array}$ & $\begin{array}{l}-0.012 \\
(-0.84)\end{array}$ \\
\hline INSPL3 & & & & $\begin{array}{l}(-0.005) \\
-0.52\end{array}$ & $\begin{array}{l}(-0.025) \\
-2.61\end{array}$ & $\begin{array}{l}(-0.008) \\
-0.55\end{array}$ \\
\hline DEMP & $\begin{array}{l}0.451 \\
(16.36)\end{array}$ & $\begin{array}{l}0.391 \\
(18.82)\end{array}$ & $\begin{array}{l}0.447 \\
(20.25)\end{array}$ & $\begin{array}{l}0.452 \\
(16.39)\end{array}$ & $\begin{array}{l}0.391 \\
(18.81)\end{array}$ & $\begin{array}{l}0.447 \\
(20.25)\end{array}$ \\
\hline DHOUR & $\begin{array}{l}0.362 \\
(16.43)\end{array}$ & $\begin{array}{l}0.291 \\
(16.48)\end{array}$ & $\begin{array}{l}0.172 \\
(9.52)\end{array}$ & $\begin{array}{l}0.38 \\
(16.37)\end{array}$ & $\begin{array}{l}0.291 \\
(16.48)\end{array}$ & $\begin{array}{l}0.172 \\
(9.52)\end{array}$ \\
\hline $\mathrm{R}^{2}$ & 0.116 & 0.116 & 0.088 & 0.115 & 0.116 & 0.088 \\
\hline
\end{tabular}

Note: "t" statistics in parentheses; regressions include year and SIC2 dummies. 
Table 3

Impact of OSHA Inspections on Injuries (any in current or last 3 years)

\begin{tabular}{llllllll} 
PERIOD & $1979-85$ & $1987-91$ & $1992-98$ & $1979-85$ & $1987-91$ & $1992-98$ \\
\cline { 2 - 7 } INTERCEP & -0.096 & 0.089 & -0.045 & -0.096 & 0.087 & -0.047 \\
& $(-6.86)$ & $(6.68)$ & $(-2.95)$ & $(-6.49)$ & $(6.38)$ & $(-3.07)$ \\
IPENX & -0.048 & -0.030 & -0.003 & & & \\
& $(-5.47)$ & $(-3.63)$ & $(-0.27)$ & & & \\
INSPX & & & & & & \\
& & & & -0.026 & -0.013 & 0.003 \\
DEMP & 0.451 & 0.392 & 0.447 & $(-3.15)$ & $(-1.72)$ & $(0.37)$ \\
& $(16.36)$ & $(18.85)$ & $(20.26)$ & 0.452 & 0.392 & 0.447 \\
DHOUR & 0.381 & 0.291 & 0.172 & $(16.39)$ & $(18.84)$ & $(20.26)$ \\
& $(16.41)$ & $(16.47)$ & $(9.52)$ & 0.381 & 0.291 & 0.172 \\
$R^{2}$ & & & & $(16.38)$ & $(16.47)$ & $(9.52)$ \\
& 0.116 & 0.116 & 0.088 & & 0.115 & 0.115 & 0.088
\end{tabular}

Note: ' $t$ ' statistics in parentheses; regressions include year and SIC2 dummies. 


\section{Table 4}

Impact of OSHA Inspections by Inspection Type

\begin{tabular}{|c|c|c|c|c|c|c|}
\hline PERIOD & $\underline{1979-85}$ & 1987-91 & $1992-98$ & 1979-85 & $1987-91$ & $1992-98$ \\
\hline INTERCEP & $\begin{array}{l}-0.096 \\
(-6.88)\end{array}$ & $\begin{array}{l}0.089 \\
(6.71)\end{array}$ & $\begin{array}{l}-0.044 \\
(-2.90)\end{array}$ & $\begin{array}{l}-0.096 \\
(-6.56)\end{array}$ & $\begin{array}{l}0.087 \\
(6.38)\end{array}$ & $\begin{array}{l}-0.046 \\
(-3.01)\end{array}$ \\
\hline IPRGPX & $\begin{array}{l}-0.043 \\
(-4.55)\end{array}$ & $\begin{array}{l}-0.035 \\
(-3.38)\end{array}$ & $\begin{array}{l}-0.005 \\
(-0.36)\end{array}$ & & & \\
\hline ICMPPX & $\begin{array}{l}-0.043 \\
(-3.15)\end{array}$ & $\begin{array}{l}-0.019 \\
(-1.73)\end{array}$ & $\begin{array}{l}-0.005 \\
(-0.43)\end{array}$ & & & \\
\hline IPRGX & & & & $\begin{array}{l}-0.016 \\
(-2.00)\end{array}$ & $\begin{array}{l}-0.010 \\
(-1.18)\end{array}$ & $\begin{array}{l}0.004 \\
(0.28)\end{array}$ \\
\hline ICMPX & & & & $\begin{array}{l}-0.033 \\
(-3.55)\end{array}$ & $\begin{array}{l}-0.012 \\
(-1.36)\end{array}$ & $\begin{array}{l}-0.001 \\
(0.10)\end{array}$ \\
\hline DEMP & $\begin{array}{l}0.451 \\
(16.36)\end{array}$ & $\begin{array}{l}0.392 \\
(18.86)\end{array}$ & $\begin{array}{l}0.447 \\
(20.26)\end{array}$ & $\begin{array}{l}0.451 \\
(16.35)\end{array}$ & $\begin{array}{l}0.392 \\
(18.84)\end{array}$ & $\begin{array}{l}0.447 \\
(20.26)\end{array}$ \\
\hline DHOUR & $\begin{array}{l}0.381 \\
(16.40)\end{array}$ & $\begin{array}{l}0.291 \\
(16.47)\end{array}$ & $\begin{array}{l}0.172 \\
(9.53)\end{array}$ & $\begin{array}{l}0.381 \\
(16.38)\end{array}$ & $\begin{array}{l}0.291 \\
(16.47)\end{array}$ & $\begin{array}{l}0.172 \\
(9.52)\end{array}$ \\
\hline $\mathrm{R}^{2}$ & 0.116 & 0.116 & 0.088 & 0.115 & 0.115 & 0.088 \\
\hline
\end{tabular}

Note: ' $\mathrm{t}$ ' statistics in parentheses; regressions include year and SIC2 dummies. 


\section{Table 5}

Impact of OSHA Inspections by Employment Size

\begin{tabular}{|c|c|c|c|c|}
\hline & $\begin{array}{l}\text { SMALL } \\
\leq 100 \\
\end{array}$ & $\begin{array}{l}\text { MEDIUM } \\
\underline{100-249}\end{array}$ & $\begin{array}{l}\mathrm{BIG} \\
\underline{250-499} \\
\end{array}$ & $\begin{array}{l}\text { VERY BIG } \\
\underline{500+}\end{array}$ \\
\hline INTERCEPT & $\begin{array}{l}-0.045 \\
(-1.77)\end{array}$ & $\begin{array}{l}-0.117 \\
(-5.88)\end{array}$ & $\begin{array}{l}-0.105 \\
(-5.19)\end{array}$ & $\begin{array}{l}-0.117 \\
(-6.19)\end{array}$ \\
\hline IPENX 1979-85 & $\begin{array}{l}-0.063 \\
(-2.78)\end{array}$ & $\begin{array}{l}-0.037 \\
(-2.39)\end{array}$ & $\begin{array}{l}-0.058 \\
(-3.46)\end{array}$ & $\begin{array}{l}-0.034 \\
(-2.23)\end{array}$ \\
\hline IPENX 1987-91 & $\begin{array}{l}-0.033 \\
(-1.87)\end{array}$ & $\begin{array}{l}-0.021 \\
(-1.36)\end{array}$ & $\begin{array}{l}-0.057 \\
(-3.16)\end{array}$ & $\begin{array}{l}-0.020 \\
(-1.30)\end{array}$ \\
\hline IPENX 1992-98 & $\begin{array}{l}0.006 \\
(0.22)\end{array}$ & $\begin{array}{l}-0.029 \\
(-1.24)\end{array}$ & $\begin{array}{l}0.003 \\
(0.16)\end{array}$ & $\begin{array}{l}0.010 \\
(0.71)\end{array}$ \\
\hline DEMP & $\begin{array}{l}0.361 \\
(14.21)\end{array}$ & $\begin{array}{l}0.469 \\
(17.35)\end{array}$ & $\begin{array}{l}0.466 \\
(15.30)\end{array}$ & $\begin{array}{l}0.449 \\
(18.18)\end{array}$ \\
\hline DHOUR & $\begin{array}{l}0.174 \\
(8.64)\end{array}$ & $\begin{array}{l}0.319 \\
(14.08)\end{array}$ & $\begin{array}{l}0.324 \\
(12.59)\end{array}$ & $\begin{array}{l}0.348 \\
(15.94)\end{array}$ \\
\hline $\mathrm{R}^{2}$ & .067 & .111 & .120 & .150 \\
\hline $\mathrm{N}$ & 21,261 & 24,424 & 18,570 & 20,738 \\
\hline
\end{tabular}

Note: ' $t$ ' statistics in parentheses; regressions include year and SIC2 dummies. Regressions for all 3 periods, separately by employment size category. 
Table 6

Impact of OSHA Inspections by Industry

$\begin{array}{lccc}\text { PERIOD } & 1979-85 & 1987-91 & 1992-98 \\ \text { SIC20PENX } & -0.050 & 0.025 & -0.021 \\ & (-2.18) & (1.09) & (-0.80) \\ \text { SIC22PENX } & -0.073 & -0.006 & 0.026 \\ & (-1.52) & (-0.13) & (0.38) \\ \text { SIC23PENX } & -0.080 & -0.078 & -0.050 \\ & (-1.10) & (-1.35) & (-0.93) \\ \text { SIC24PENX } & -0.012 & -0.101 & -0.008 \\ & (-0.41) & (-3.88) & (-0.21) \\ \text { SIC25PENX } & -0.058 & -0.016 & 0.027 \\ & (-1.44) & (-0.41) & (0.56) \\ \text { SIC26PENX } & 0.026 & -0.007 & 0.019 \\ & (0.77) & (-0.18) & (0.44) \\ \text { SIC27PENX } & -0.099 & -0.045 & -0.084 \\ & (-1.78) & (-0.93) & (-1.69) \\ \text { SIC28PENX } & -0.014 & 0.008 & -0.047 \\ & (-0.38) & (0.16) & (-0.89) \\ \text { SIC29PENX } & -0.073 & -0.033 & -0.104 \\ & (-1.06) & (-0.41) & (-1.01) \\ \text { SIC30PENX } & -0.058 & -0.061 & 0.010 \\ \text { SIC31PENX } & (-1.34) & (-1.83) & (0.26) \\ \text { SIC32PENX } & -0.097 & -0.079 & -0.059 \\ \text { SIC33PENX } & (-1.68) & (-1.20) & (-0.78) \\ \text { SIC34PENX } & -0.094 & 0.004 & 0.059 \\ \text { SIC35PENX } & (-2.92) & (0.14) & (1.22) \\ \text { SIC36PENX } & -0.105 & -0.031 & -0.015 \\ \text { SIC37PENX } & (-3.98) & (-1.20) & (-0.45) \\ & -0.030 & -0.041 & -0.002 \\ & (-1.44) & (-2.10) & (-0.05) \\ & -0.071 & -0.040 & -0.003 \\ & (-3.05) & (-1.64) & (-0.09) \\ & -0.064 & -0.066 & 0.044 \\ & (-1.88) & (-1.91) & (1.15) \\ & 0.022 & -0.038 & 0.044 \\ & 0.023 & 0.073 & 0.026 \\ & (0.29) & (1.04) & (0.45) \\ & -0.012 & 0.005 & -0.037 \\ & (-0.28) & (0.91) & (-0.80)\end{array}$

Note: ' $t$ ' statistics in parentheses; coefficients from one regression combining all 3 periods. SIC 21 contains few establishments, so it's combined with SIC 20. 


\section{Table 7}

Correlations of Industry-Specific Inspection Effects with Other Variables

$\begin{array}{lll}\text { Industry } & \text { Industry } & \text { Industry } \\ \text { Investment } & \text { Lost Workday Inspection } \\ \text { Rate } & \underline{\text { Injury Rate }} \quad \underline{\text { Rate }}\end{array}$

Inspection Impact

.22

.05

$-.05$

by Industry

$(.71)$

(.73)

(all establishments)

$-.05$

$(.71)$

.02

$-.21$

by Industry

(.89)

$($ employment $<250)$

Notes:

'p' values in parentheses.

Inspection impact by industry measured by coefficients in Table 6

(and similar estimates for the subsample of establishments with employment $<250$ ).

The sample included 19 industries in 3 time periods $(\mathrm{N}=57)$. 


\section{Table 8}

Impact of OSHA Inspections on Injury Types:

Days Away from Work (DAW) vs. Restricted Work Activity (RWA)

\begin{tabular}{lll} 
& $\underline{\text { DAW Rate }}$ & \multicolumn{1}{l}{ RWA Rate } \\
INTERCEPT & -0.120 & 0.069 \\
& $(-11.08)$ & $(6.35)$ \\
IPENX 1979-85 & -0.050 & -0.003 \\
& $(-5.62)$ & $(0.29)$ \\
IPENX 1987-91 & -0.038 & 0.017 \\
& $(-4.50)$ & $(2.01)$ \\
IPENX 1992-98 & -0.014 & 0.004 \\
& $(-1.33)$ & $(0.35)$ \\
DEMP & 0.413 & 0.161 \\
& $(29.98)$ & $(11.60)$ \\
DHOUR & 0.233 & 0.107 \\
$\mathrm{R}^{2}$ & $(20.28)$ & $(9.26)$ \\
$\mathrm{N}$ & .086 & .016 \\
& 84,993 & 84,993
\end{tabular}

Notes: ' $t$ ' statistics in parentheses; regressions include year and SIC2 dummies.

Regression includes all 3 periods of data. 
Table 9

Declines in Specific Injury Types, 1992-98

\begin{tabular}{|c|c|c|c|c|c|c|}
\hline & Total & A & B & $\mathrm{C}$ & \multicolumn{2}{|l|}{$\begin{array}{l}\text { Sum } \\
A+B+C\end{array}$} \\
\hline & All & Bodily & Falls & Struck & & \\
\hline & Injuries & Reaction & Same-level & Against & & \\
\hline 1992 & 352.1 & 163.8 & 25.4 & 27.3 & \multicolumn{2}{|l|}{216.5} \\
\hline 1998 & 204.9 & 92.8 & 17.0 & 15.5 & \multicolumn{2}{|l|}{125.3} \\
\hline \multicolumn{7}{|c|}{$\begin{array}{l}\text { Decrease } \\
(\%) \quad 42 \%\end{array}$} \\
\hline & $\mathrm{D}$ & E & $\mathrm{F}$ & G & $\mathrm{H}$ & $\begin{array}{l}\text { Sum } \\
D+E+F+G+H\end{array}$ \\
\hline & $\begin{array}{l}\text { Caught } \\
\text { In }\end{array}$ & $\begin{array}{l}\text { Falls } \\
\text { Lower-level }\end{array}$ & $\begin{array}{l}\text { Struck } \\
\text { By }\end{array}$ & $\begin{array}{l}\text { Eye } \\
\text { abrasions }\end{array}$ & \multicolumn{2}{|c|}{$\begin{array}{l}\text { Harmful } \\
\text { exposures }\end{array}$} \\
\hline 1992 & 27.5 & 11.6 & 47.0 & 8.8 & 18.1 & 113.0 \\
\hline 1998 & 18.6 & 6.9 & 29.5 & 4.6 & 10.0 & 69.6 \\
\hline $\begin{array}{l}\text { Decre } \\
(\%)\end{array}$ & $32 \%$ & $41 \%$ & $37 \%$ & $48 \%$ & $45 \%$ & $38 \%$ \\
\hline
\end{tabular}

Note:

Event types A, B, and C were identified by OSHA staff as those less likely to have injuries related to OSHA standards. The case is strongest for category A.

Event types D, E, F, G, and $\mathrm{H}$ were identified as types more likely to have injuries related to OSHA standards. The case is strongest for categories $\mathrm{D}$ and $\mathrm{G}$.

Combined, these 8 categories included 95\% of all days away from work injuries in 1998. 
Figure 1

Changes in the Manufacturing Lost Workday Injury Rate per 100 Full-time

Workers and Its Components

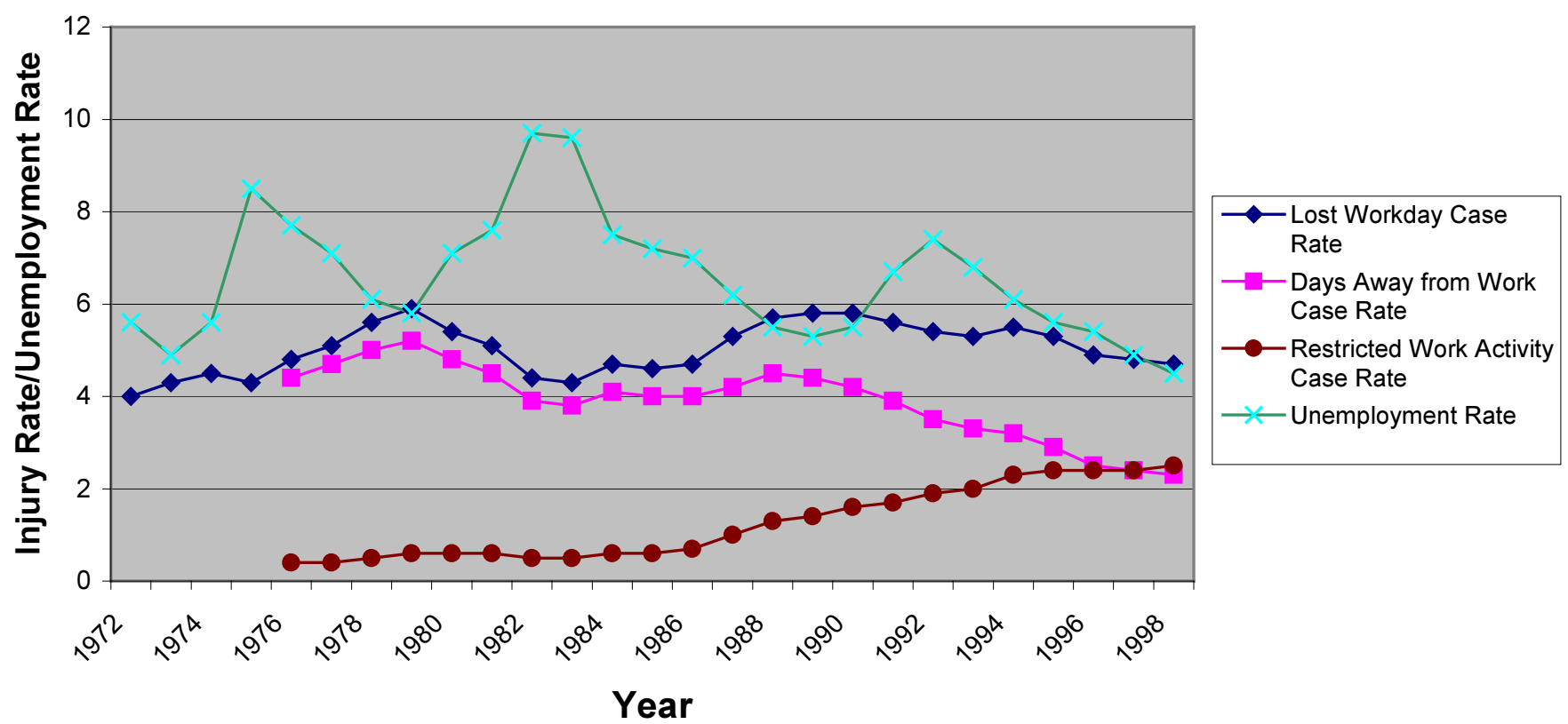

